\title{
Examination of the Levels of Digital Game Dependency of the Students of the Faculty of Sports
}

\author{
M. Fatih Karahuseyinoglu ${ }^{1}$ \\ Oguzhan Altungul ${ }^{2}$ (D) \\ Eyyup Nacar's \\ Omer Faruk Tutar ${ }^{4}$ (D)
}

${ }_{1,2, s}$ Faculty of Physical Education and Sport Sciences, Firat University, Turkey. Email.fkarahuseyinoglu@gmail.com Tel. 00905053459525 sEmail: oaltingul@firat.edu.tr

"Institute of Health Sciences, Firat University, Turkey.

•Email:tutar10476549@hotmail.com

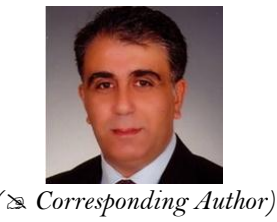

\section{Abstract}

The aim of our study was to examine the digital game addiction levels of the students of the Faculty of Sports Sciences in terms of some variables. The research group of our study consists of 397 randomly selected undergraduate students studying at Firat University Faculty of Sports Sciences and Inonu University Faculty of Sports Sciences in 2019. Frequency of variables (f) and percentage (\%) distributions were calculated and two-way variance analysis (ANOVA) was used in multiple group variables and t-test was used for the significance of the difference between the two independent groups. Tukey test was used to determine which groups it was among in the analysis in which significant differences were detected. According to the findings of our study, undergraduate students studying in the departments of Firat University Faculty of Sports Sciences and Inonu University Faculty of Sports Sciences; It was determined that there was no statistically significant difference in the level of digital game dependency of the undergraduate students depending on the department, class, gender and age variables in which they studied. There was a statistically significant difference between digital game dependency levels based on the state of playing the digital game and the daily playing time variables. In line with the study findings, digital game addiction with an average of 2.29 on the digital game addiction scores of undergraduate students studying at Firat University Faculty of Sports Sciences and Inonu University Faculty of Sports Sciences levels were below average.

Keywords: Sports, Digital gaming, Addiction, E-Sport.

Citation | M. Fatih Karahuseyinoglu; Oguzhan Altungul; Eyyup Nacar; Omer Faruk Tutar (2020). Examination of the Levels of Digital Game Dependency of the Students of the Faculty of Sports. Asian Journal of Education and Training, 6(1): 18-22. History:

Received: 7 October 2019

Revised: 11 November 2019

Accepted: 16 December 9019

Published: 14 Janem 2019

Published: 14 January 2020
Licensed: This work is licensed under a Creative Commons

Licensed: This work is
Attribution 3.0 License (cc) E

Publisher: Asian Online Journal Publishing Group
Acknowledgement: All authors contributed to the conception and design of the study.

Funding: This study received no specific financial support.

Competing Interests: The authors declare that they have no conflict of interests.

Transparency: The authors confirm that the manuscript is an honest, accurate, and transparent account of the study was reported; that no vital features of the study have been omitted; and that any discrepancies from the study as planned have been explained.

Ethical: This study follows all ethical practices during writing.

\section{Contents}

1. Introduction

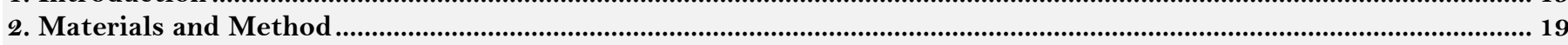

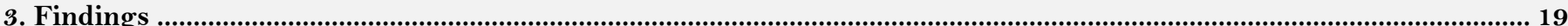

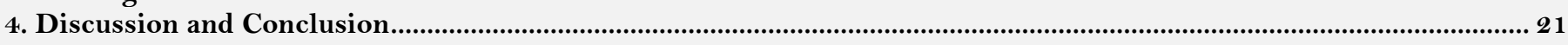

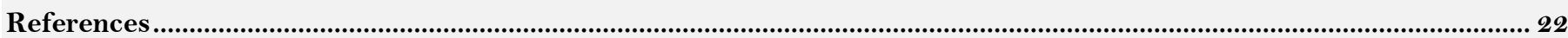




\section{Contribution of this paper to the literature}

This study contributes to the existing literature by examining the digital game addiction levels of the students of the Faculty of Sports Sciences in terms of some variables.

\section{Introduction}

The development of technology also leads to various changes in our lives. Technology provides convenience in many subjects in our lives with the development of it. When looking at the early periods when technology began to develop, it is seen that computers the size of a room were built. However, with the development of technology, this situation has become very small inventions and has developed a lot today. The development of technology has started to have a great impact on people not only by producing devices, but also with the development of applications and games that are installed in the memory of these devices. These applications, which we call digital games, have become people's free time appraisal activities. A new formation has begun in the sports community with the development of the games every day. This formation is called E-sports (Electronic sports). E-sports are defined as organizations organized by internationally recognized games anywhere in the world, via a console or computer, over the internet or by coming together with platforms anywhere in the world. There is competition in these tournaments (Argan et al., 2007).

Although the beginning of e-sports was based on the emergence of the first computer games, its popularity has increased for about 9-10 years. The atmosphere of the games created by young people in the game center arcades established in 1970 constitutes the culture of E-sports. The game consoles that developed afterwards resulted in the mutual struggles of the two people. This is the beginning of the creation of a competitive environment in the history of e-sports. In the following periods, with the establishment of internet cafes, many computers came side by side and some games were played together in the same playground as the servers and individuals at the computer. In the following times, people started to compete in games online without coming together with the developing technology, and as a result, competitions were organized by putting different prizes. In Europe, the 1997 "Red Annihilation" tournament was the beginning of the award for competitions (Kocadağ, 2017). The prize money, which was as low as $\$ 1,500-2000$ during those periods, was worth $\$ 20,770,460$ in the prize pool for the International in 2016, and the first-place team in the competition won $\$ 9,139,000$ (Font and Mahlmann, 2019). This situation is inevitably becoming an industry in individuals. It increases interest in digital games and causes people to become addicted and not leave game consoles and computers for days. Undoubtedly, this situation affects people in terms of health as well as disconnected from the outside world and makes them anti-social. People are unable to communicate correctly with the people around them, and this condition, which starts at an early age, affects children's futures from levels of assertiveness to self-esteem. It will cause health problems as a result of inactivity.

It is important for parents to be careful when it is considered that this type of play dependency of children and young people will cause problems for children in both health and social terms in the future. For this reason, our study aimed to examine the digital game dependency levels of students studying at the faculty of sports science.

\section{Materials and Method}

The research universe consists of undergraduate students studying at Firat University Faculty of Sports Sciences and inonu University Faculty of Sports Sciences in 2019. The sample of the study consisted of 397 randomly selected undergraduate students from the specified departments; Firat University Sports Sciences and Inonu University Faculty of Sports Sciences, department of physical education teaching, sports management department, department of coaching education, department of exercise and sports education for the disabled. "Personal information form" (department, digital gaming status and daily playing time, age, gender, class) was used to determine the demographic information of the subjects involved in the study and the "DOBÖ-7" which is a 7-point scale was used that developed by Lemmens and his colleagues. The likert type of the scale developed is a 5degree, single-factor structure. The total number of points to be collected between the scale 1 and 5 points is between 7 and 35 points. Monothetic and polythetic diagnosis were used to say that a young person is addicted to digital games according to the scale. According to the monothetic diagnosis, if a person scores three (sometimes) points and more on seven of the seven items; according to the polythetic diagnosis, if it gives scores of three(sometimes) points and more to at least four of the seven items, it is defined as a digital game addict. DOBÖ7's validity and reliability values were found to be $0.92 \mathrm{CFI}=0.904$, RMSEA $=0.053(90 \% \mathrm{CI}=0.049$ and 0.056$)$ for Cronbach alpha and have been shown to be available in adolescents.

\subsection{Analysis of Data}

The analysis of the data in the research and the calculation of the results found were created by statistical programs in computer environment. Frequency of variables (f) and percentage (\%) distributions have been calculated. It was checked by skewness and kurtosis tests to determine whether the data were distributed normally. As a result of these tests and controls, the data of the research were determined to be parametric. Tukey test results were used to determine which groups the difference was among the results with significant differences. The error level in the study was taken as $\mathrm{p}<0,05$.

\section{Findings}

Findings on the variables of the study are given in this section. The findings showing the distribution of undergraduate students studying in Firat University and Inonu University Faculties of Sports Sciences according to their individual status as of 2019 were examined and interpreted. 
Table-1. Demographic characteristics distribution table.

\begin{tabular}{|c|c|c|c|}
\hline Variable & Information form & $\mathbf{N}$ & $\%$ \\
\hline \multirow{5}{*}{ Department } & Coaching & 124 & 31,2 \\
\hline & Teaching & 137 & 34,5 \\
\hline & Exercise and Sports Training for Disabilities & 57 & 14,4 \\
\hline & Management & 79 & 19,9 \\
\hline & Total & 397 & 100,0 \\
\hline \multirow{4}{*}{ Age } & 17-19 Years & 65 & 16,4 \\
\hline & 20-22 Years & 200 & 50,4 \\
\hline & 23 Years and above & 132 & 33,2 \\
\hline & Total & 397 & 100,0 \\
\hline \multirow{5}{*}{ Class } & 1st Class & 99 & 24,9 \\
\hline & 2nd Class & 89 & 22,4 \\
\hline & 3rd Class & 128 & 32,2 \\
\hline & 4th Class & 81 & 20,4 \\
\hline & Total & 397 & 100,0 \\
\hline \multirow{3}{*}{ Gender } & Male & 226 & 56,9 \\
\hline & Female & 171 & 43,1 \\
\hline & Total & 397 & 100,0 \\
\hline Digital Game & Computer & 179 & 45,1 \\
\hline \multirow[t]{2}{*}{ Platform } & Phone & 218 & 54,9 \\
\hline & Total & 397 & 100,0 \\
\hline \multirow{4}{*}{ How many hours a day do you play? } & $1-2$ hours 182 & 182 & 45,9 \\
\hline & $3-4$ hours 151 & 151 & 38,1 \\
\hline & 5 hours and more 64 & 64 & 16,0 \\
\hline & Total & 397 & 100.0 \\
\hline
\end{tabular}

Source: N: 397 .

\subsection{Percentage Distribution of the Subjects.}

When the demographic distribution table of the students is examined in Table 1; Among the age groups, the highest participation was between $50.4 \%$ and $20-22$ years, while the lowest participation was between $16.4 \%$ and 17-19 years. When the subjects who participated in the study were examined, it was observed that the Physical Education and Sports Teaching department provided the highest participation with 34.5\%, and the Department of Exercise and Sports Education for the Disabled with 14.4\%. When we look at the distribution of the classes they are studying, it is seen that 3rd Grade students constitute 32.2\%, 1st Grade 24.9\%, 2nd Grade, 22,4\% and 4th Grade $20.4 \%$ subject group, respectively. When the gender of the participants was examined, $56.9 \%$ of the subject group was male and $43.1 \%$ were female. When the demographic distribution table was examined, they said that $54.9 \%$ of them were playing digital games when checked answers of the question 'do you play digital games'? It has been observed that the majority of students $(84 \%)$ devote time to digital play for no less than 4 hours per day.

Table-2. Anova Test table of digital game addiction averages by department at university.

\begin{tabular}{c|c|c|c|c|c|c}
\hline & Department & $\mathbf{N}$ & $\mathbf{X}$ & $\mathbf{S s}$ & $\mathbf{f}$ & $\mathbf{p}$ \\
\hline & Coaching & 124 & 2,35 &, 980 & 1,972 & 0,118 \\
\hline Digital Game & Teaching & 137 & 2,18 &, 931 & & \\
\hline Addiction & Disabilitie & 57 & 2,17 &, 877 & & \\
& Management & 79 & 2,46 &, 955 & & \\
\hline
\end{tabular}

When Table 2 was examined, it was determined that the difference between the participants' levels of digital game dependence and the department variable in which they were studying was not statistically significant $(\mathrm{p}>0.05)$.

Table-3. Anova test table of digital game addiction averages by university classes.

\begin{tabular}{c|c|c|c|c|c|c}
\multicolumn{6}{c}{ Table-3. Anova test table of digital game addiction averages by university classes. } \\
\hline & Class & $\mathbf{N}$ & $\mathbf{X}$ & $\mathbf{S s}$ & $\mathbf{f}$ & $\mathbf{p}$ \\
\hline & 1st Class & 99 & 2,29 &, 906 & 2,233 & 0,84 \\
\hline Digital Game & 2nd Class & 89 & 2,22 &, 965 & & \\
\hline Addiction & 3rd Class & 128 & 2,44 & 1,007 & & \\
& 4th Class & 81 & 2,10 &, 855 & & \\
\hline & Total & 397 & 2,29 &, 948 & & \\
\hline
\end{tabular}

Note: One way anova, $\mathrm{p}<0.05$

When Table 3 was examined, the difference between participants' digital game dependency levels and class levels variables was not statistically significant $(\mathrm{p}>0.05)$.

Table-4. Anova test table on digital gaming addiction averages by age of students at university.

\begin{tabular}{c|c|c|c|c|c|c}
\hline & Age & N & X & Ss & $\mathbf{f}$ & $\mathbf{p}$ \\
\hline \multirow{2}{*}{ Digital Game Addiction } & $17-19$ & 65 & 2,10 &, 937 & 1,607 & 0,202 \\
& $20-22$ & 200 & 2,35 &, 930 & & \\
& 23 Years and above & 132 & 2,28 &, 975 & & \\
\cline { 2 - 7 } & Total & 397 & 2,29 &, 948 & & \\
\hline \multirow{2}{*}{ Note: One way ay } & & & & \\
\hline
\end{tabular}

Note: One way anova, $\mathrm{p}<0.05$. 
When Table 4 was examined, the difference between participants' digital game dependency levels and age variables was not statistically significant $(\mathrm{p}>0.05)$.

Table-5. T test table of digital game addiction averages by gender of students at university.

\begin{tabular}{c|c|c|c|c|c|c}
\hline & Gender & $\mathbf{N}$ & $\mathbf{X}$ & $\mathbf{S s}$ & $\mathbf{t}$ & $\mathbf{p}$ \\
\hline \multirow{2}{*}{ Digital Game Addiction } & Male & 226 & 2,34 &, 966 & 1,348 & 0,179 \\
\cline { 2 - 7 } & Female & 171 & 2,21 &, 920 & & \\
\hline
\end{tabular}

When Table 5 was examined, the difference between participants' digital game dependency levels and gender variables was not statistically significant $(\mathrm{p}>0.05)$.

Table-6. T test table of digital game addiction averages based on university students' participation in digital game.

\begin{tabular}{c|c|c|c|c|c|c}
\hline & Digital Game Platform & $\mathbf{N}$ & $\mathbf{X}$ & $\mathbf{S s}$ & $\mathbf{t}$ & $\mathbf{p}$ \\
\hline Digital Game & Computer & 179 & 1,71 &, 698 & $-13,041$ &, 000 \\
\hline Addiction & Phone & 218 & 2,76 &, 863 & & \\
\hline Note: Independent sample T-test, $\mathrm{p}<0.05$.
\end{tabular}

Note: Independent sample T-test, $\mathrm{p}<0.05$.

The participants' digital game dependency levels and the digital game platform question variable were examined in Table 6, it was determined that there was a statistically significant difference between those who played the game on a computer and those who played the game with the phone $(\mathrm{p}<0.05)$.

Table-7. Digital game dependencies averages $\mathrm{T}$ test results by time to participate in digital game.

\begin{tabular}{c|c|c|c|c|c|c|c}
\hline & Playing Period & N & X & Ss & f & p & Tukey \\
\hline & $1-2$ Hours $^{\mathrm{A}}$ & 182 & 2,28 &, 780 & 54,704 & 0,00 & $\mathrm{~A}-\mathrm{B}, \mathrm{C}$ \\
\hline Digital Game & $3-4$ Hours $^{\mathrm{B}}$ & 151 & 2,95 &, 615 & & & \\
\hline Addiction & 5 Hours and more & & \\
\hline
\end{tabular}

When Table 7 was examined, it was determined that there was a statistically significant difference between the group playing 1-2 hours and the participants who played 3-4 hours and played 5 hours or more when the participants' digital game dependency levels and game time variable levels were examined $(\mathrm{p}<0,05)$.

\section{Discussion and Conclusion}

In this part of our study, the undergraduate students studying at Firat University Faculty of Sports Sciences and Inonu University Faculty of Sports Sciences who participated in the study, have a variety of variables in terms of the level of digital game dependency. Based on the hypothesis that it differs, the data of the study will be discussed in this section.

The $50.4 \%$ of students are studying between the ages of 20 and $22,34.5 \%$ in physical education and sports teaching department, and $14.4 \%$ in the newly opened Department of Exercise and Sports Education for the newly opened Disabled people in Turkey. When we look at the distribution of the classes they are studying, it is seen that 3rd Grade students constitute 32.2\%, 1 st Grade 24.9\%, 2nd Grade, 22,4\% and 4th Grade 20.4\% subject group, respectively. When the gender of the participants was examined, $56.9 \%$ of the subject group was male and $43.1 \%$ were female. When the demographic distribution table was examined, they said that $54.9 \%$ of them were playing digital games when checked answers of the question 'do you play digital games?

When the Anova test results were examined according to the variables of the departments in which the subjects participated in the study, the difference between the participants' levels of digital game dependence and the department variable in which they were studied was considered statistically not significant. Looking at the average score, it is seen that the students of the management department have the highest score. However, it is observed that all departments remain below the average of dependency points.

When the Anova test results were examined according to the class groups' variable of the subjects who participated in the study, the difference between the participants' digital game dependency levels and the class group variables was not statistically significant. When the class groups of the participants were examined, it was seen that the average scores of the students studying in 3rd grade were higher than in other class groups. However, it is observed that the average points are not at the level of dependency according to our scale. In a study similar to our study (Tanrıverdi, 2012) they found that there was no statistically significant difference between the level of game addiction according to the class groups variable of the participants in their studies on game addiction.

When the Anova test results were examined according to the age group variable of the subjects who participated in the study, the difference between the participants' digital game dependency levels and the age variable was not statistically significant. Looking at the average scores, it was found that students between the ages of 20 and 22 had higher digital game addiction scores than other age groups, but they remained below the level of digital gaming dependency. In a study (Aydoğdu, 2018) that did not parallel with our study, he found that there was a statistically significant difference in age groups variable in the study of examining the digital game dependencies of children playing digital games in terms of various variables. According to the results of the Aydoğdu (2018) children between the ages of 11 and 12 have higher levels of digital gaming addiction than children between the ages of 13 and 14. In this study which is not similar to our study, it can be said that the participants were in childhood and that our study was due to the fact that we examined the levels of digital game addiction of the participants at the university level.

When the $t$ test results were examined according to the gender variable of the subjects who participated in the study, the difference between the participants' digital game dependency levels and the gender variable was not statistically significant. Male participants were found to have higher digital game addiction points averages than 
female participants. In a study similar to our study (Inal and Cağıltay, 2005; Cakır et al., 2011; Horzum, 2011; Sahin and Tugrul, 2012; Li and Wang, 2013) the average game addiction scores were higher in boys than girls.

When the t-test results were examined according to the variables of the digital game playing platforms of the subjects participating in the study, when the participants' digital game dependency levels and the platform question variable in which they played the digital game were examined, it was determined that the difference between those who played the game on the phone and those playing on the computer was statistically significant. Looking at the average points of the answers given to the question of digital game playing platforms, it was found that the participants who played the game on the phone were higher in proportion to the participants who played the game on the computer. We can say that this is because mobile phones are in our lives all the time and we also carry them with us all the time and can be used in any environment in free time.

When the results of the anova test were examined according to the game time variable of the subjects participating in the study, the group playing 1-2 hours between the participants' digital game dependency levels and the game play time variable and playing for 3-4 hours and 5 hours or more the difference between the group playing was statistically significant. When the group scores are examined, it is seen that the group playing games in the range of 3-4 hours per day is close to the average of dependency points, but not at the level of digital game dependency. It has been found that the group that plays games 5 hours or more has higher levels of dependence on digital gaming dependency, which is based on the digital game dependency averages.

Undergraduate students studying in the departments of Firat University Faculty of Sports Sciences and Inonu University Faculty of Sports Sciences; Depending on the department, class, gender and age variables in which they studied, it was determined that there was no statistically significant difference in the level of digital game dependency of the undergraduate students. There was a statistically significant difference between digital game dependency levels based on the state of playing the digital game and the daily playing time variables. In line with the study findings, digital game addiction with an average of 2.29 on the digital game addiction scores of undergraduate students studying at Firat University Faculty of Sports Sciences and Inonu University Faculty of Sports Sciences levels were below average.

Mobile phones, game consoles, and computers are used as leisure assessment tools. The dependence of individuals on such devices is inevitable to reveal various health problems and the state of anti-social status. Individuals will contribute to their health in terms of sports requiring physical action in leisure activities. It is thought that the unconscious construction of E-sports, which is called a sport and has a federation in our country, will create significant health problems in the coming years. Digital games banned or restricted in most countries, those games can be played in our country without any obstacles. It is very important that our Goverment and families inform our children and young people about this issue and those such games are restricted. For these reasons, it was deemed necessary to examine the digital game addiction levels of the students in the study group and as a result of the available research; it is thought to contribute to sports scientists, psychologists, and academicians working on this subject. Since there were no desired levels of study in the literature on the subject in this section of our research, not many sources could be reached. In this aspect of the research, it can be said that it will contribute to field writing.

\section{References}

Argan, M., H.K. Suher, A. Ozer, E.v. Akin and T. A.M., 2007. Game quality: Astudy on Turkish game players. Sarajevo, Bosnia Herzegovina: 2nd International Symposium of New Technologies in Sport.

Aydoğdu, F., 2018. Analyzing digital gaming dependencies of children playing digital games in terms of various variables. Ulakbilge, 6(31): $1-18$.

Cakır, Ö., T. Ayas and M.B. Horzum, 2011. An investigation of university students' internet and game addiction with respect to several variables. Ankara University, Journal of Faculty of Educational Sciences, 44(2): 95-117.Available at: https://doi.org/10.1501/egifak_OOOOOO1226.

Font, J.M. and T. Mahlmann, 2019. Dota 2 bot competition. In IEEE Transactions on Games, 11(3): 285-289.

Horzum, M.B., 2011. Examining the computer game dependency levels of primary school students according to various variables. Education and Science, 36(159): 56-68.

Inal, Y. and K. Cağlltay, 2005. Factors affecting the computer game playing habits and game preferences of elementary school students. New Directions in Education- II. Game in Education Symposium. Ankara, 14: 114-115.

Kocadağ, M., 2017. Electronic sports career and education. Journal of Trends in Eastern Anatolia Social Sciences, 1(2): 49-63.

$\mathrm{Li}$, H. and S. Wang, 2013. The role of cognitive distortion in online game addiction among Chinese adolescents. Children and youth services review, 35(9): 1468-1475.Available at: https://doi.org/10.1016/j.childyouth.2013.05.021.

Sahin, C. and V.M. Tugrul, 2012. Examining computer game addiction levels of elementary school students. Journal of the World of Turks / Journal of World of Turks, 4(3): 115-130.

Tanriverdi, S., 2012. Examining the relationship between internet addiction and perceived social support in secondary school students. Unpublished Master's Thesis. The University of Yüzüncüyıl, Institute of Educational Sciences: Van. 